\title{
PENGARUH METODE PAKEM DALAM MENINGKATKAN MOTIVASI BELAJAR SISWA KELAS V SD NEGERI 124 BATUASANG
}

\section{THE EFFECT OF THE PAKEM METHOD IN INCREASING THE LEARNING MOTIVATION OF CLASS V STUDENTS OF SD NEGERI 124 BATUASANG}

\author{
oleh \\ Jainuddin', Mubarik², Syaiful Bahri ${ }^{3}$ \\ Email: jainuddin@universitasbosowa.ac.id \\ ${ }^{1}$ Pendidikan Matematika, Universitas Bosowa \\ ${ }^{2}$ Pendidikan Matematika, Universitas Tadulako \\ ${ }^{3}$ MAN Nagekeo, KementrianAgama Kabupaen Nagekeo
}

\begin{abstract}
ABSTRAK
Penelitian ini dilatarbelakangi oleh pandemi yang berkepanjangan dan menutup berbagai sekolah mulai dari sekolah dasar sampai sekolah tinggi. Sehingga diperlukan adanya terobasan terbaru dalam metode pembelajaran yang dapat meninkatkan motviasi siswa untuk Kembali belajar. Seperti halnya pada siswa kelas V SD yang sudah lama meninggalkan sekolah. Diharapkan dengan metode yang tepat dapat meningkatkan kembali motivasi belajar siswa. Salah satu metode yang di anggap tepat oleh peneliti adalah metode PAKEM. PAKEM adalah singkatan dari Pembelajar Aktif, Kreatif, Efektif dan Menyenangkan. Jenis penelitian ini adalah penelitian lapangan (field research), yaitu penelitian yang dilakukan dengan terjun langsung ke lapangan untuk meneliti pengaruh penggunaan metode PAKEM terhadap motivasi belajar siswa. Metode yang digunakan dalam penelitian ini adalah metode eksperimen, desainnya adalah "pre-test dan post-test one group design". Hasil penelitian menunjukkan bahwa ada peningkatan motivasi belajar setelah penggunaan metode PAKEM yang dilaksanakan pada siswa kelas V SD Negeri 124 Batuasang.
\end{abstract}

Kata Kunci : Pakem, Motivasi, Belajar

ABSTRACT

This research was motivated by a prolonged pandemic and closed various schools ranging from elementary to high schools. So it is necessary to have the latest breakthroughs in learning methods that can increase student motivation to return to learning. As is the case with grade V SD students who have long left school. It is expected that the right method can increase student motivation again. One method that researchers consider appropriate is the PAKEM method. PAKEM stands for Active, Creative, Effective and Fun Learner. This type of research is field research, which is research conducted by going directly to the field to examine the effect of using the PAKEM method on student learning motivation. The method used in this research is an experimental method, the design is "pre-test and post-test one group design". The results showed that the increase in learning motivation after using the PAKEM method was implemented in grade V SD Negeri 124 Batuasang.

Jumal Ilmiah Ecosystem Volume 21 Nomor 1, Januari -April 2021 
Keyword: PAKEM, Motivation, Learning

\section{A. PENDAHULUAN}

Covid-19 sudah melanda dunia lebih dari 1 tahun, segala aktivitas berhanti dan jalan di tempat. Mulai dari aktivitas sehari-hari sampai dengan aktivitas Pendidikan dari sekolah dasar sampai sekolah tinggi. Masa pandemi Covid 19, Pendidikan dari sekolah dasar sampai sekolah tinggi sangat merasakan dampaknya. Sekolah-sekolah ditutup untuk menghindari dari pandemic Covid 19. Pandemi ini mengubah bentuk proses pembelajaran dari luring ke daring. Banyak kalangan Pendidikan yang gagap akan hal ini. Mulai dari yang gaptek akan teknologi, kekurangan alat, sampai ketidak tersediaan jaringan.

Pendidikan tetap harus berjalan seperti biasanya walaupun itu harus lewat daring. Di tengah pandemi yang terus melaju, dunia Pendidikan harus terus mendapatkan perhatian khusus agar tidak terdampak buruk. Apabila membahas tentang dunia pendidikan, maka akan membahas masa depan suatu bangsa. Melihat dari kacamata umum sekarang ini, pandemi covid-19 memang banyak menimbulkan ancaman bagi dunia pendidikan, namun dapat dilihat dari sudut pandang yang berbeda, sehingga ancaman dapat diubah menjadi dampak peluang untuk memajukan dunia pendidikan.

Pendemi covid-19 telah mengubah dunia pendidikan mulai dari proses pembelajaran, dimana biasanya dilakukan di dalam kelas dengan tatap muka, namun sejak pandemi berlangsung berubah menjadi belajar daring (dalam jaringan). Guru, siswa dan orang tua dituntut untuk bisa menghadirkan proses pembelajaran yang efektif dan aktif walaupun dilaksanakan dari rumah masing-masing.

Pendidikan adalah suatu upaya yang terus menerus dan tidak pernah berhenti yang harus dilaksanakan, baik itu oleh seorang individu maupun institusi. Namun setiap individu maupun institusi selalu menjadikan pendidikan ini sebagai suatu keharusan yang diterima oleh semua pihak (Delila, 2017). Proses pendidikan yang mengandalkan tatap muka saja merupakan metode pengajaran tradisional yang berjalan lambat dan tidak seiring 
dengan perkembangan zaman (Winda, 2016).

Menurut Khair (dalam Pradnyawathi, 2019) pembelajaran merupakan kegiatan pendidikan yang berfungsi dalam membantu pertumbuhan dan perkembangan anak agar tumbuh ke arah yang positif. Kegiatan pembelajaran yang dilakukan secara menyenangkan menimbulkan proses belajar yang efektif sehingga mendorong siswa lebih termotivasi untuk terus belajar sendiri tanpa diperintah dan tidak merasa terpaksa dalam mengikuti pembelajaran. Oleh sebab itu perlu diterapkan metode pembelajaran yang bisa menjadi solusi pemecahan masalah tersebut yang dipandang perlu adanya variasi suatu pembelajaran. Salah satunya yang dimaksud ialah menerapkan model pembelajaran PAKEM (Laksmi, 2020).

Untuk mengatasi permasalahan ini di perlukan alternatif dalam pembelajaran yaitu menggunakan metode pembelajaran aktif, kreatif, efektif dan menyenangkan (PAKEM). Guru di tuntut mampu menciptakan suasana belajar yang menyenangkan, sehingga peserta didik ikut aktif dalam proses pembelajaran dan kreatif dalam menyelesaikan tugas-tugas yang diberikan oleh guru. Keberhasilan pembelajaran Bahasa Indonesia di sekolah dasar sangat dipengaruhi oleh peran guru dalam proses pembelajaran. Jika guru memahami dengan benar konsep Bahasa Indonesia dan guru dapat memberikan motivasi peserta didik untuk mengikuti proses pembelajaran maka tujuan pembelajaran di sekolah dapat tercapai dengan optimal (Ismail, 2019).

PAKEM adalah singkatan dari Pembelajar Aktif, Kreatif, Efektif dan Menyenangkan. Aktif diartikan bahwa dalam kegiatan pembelajaran harus menciptakan suasana sedemikian rupa sehingga peserta didik aktif dalam mengajukan pertanyaan, mengemukakan gagasan, mencari data dan informasi yang mereka perlukan untuk memecahkan masalah. Kreatif artinya guru menciptakan kegiatan pembelajaran yang beragam sehingga memenuhi tingkat kemampuan siswa. Efektif yaitu tidak menghasilkan apa yang harus dikuasai setelah proses pembelajaran berlangsung, sebab pembelajaran memiliki sejumlah tujuan pembelajaran yang harus dicapai. Menyenangkan adalah suasana pembelajaran yang menyenangkan dan nyaman bagi peserta didik sehingga 
peserta didik memusatkan perhatian secara penuh sehingga waktu curah perhatiannya tinggi (Ismail, 2019).

$$
\text { Menurut Zahara }
$$

Pembelajaran PAKEM adalah singkatan dari Pembelajaran Aktif, Kreatif, Efektif, Dan Menyenangkan: Pembelajaran Aktif adalah pembelajaran yang berpusat pada siswa (learning oriented), proses pembelajaran yang mengarahkan bagaimana siswa belajar secara aktif baik mental maupun fisik

Pembelajaran Kreatif adalah pembelajaran yang memberikan ruang pada peseeta didik untuk memunculkan kreatifitasnya dalam memecahkan masalah yang dihadapinya. Pembelajaran Efektif, Efektif dalam pembelajaran adalah proses pembelajaran yang ditempuh secara aktif, kreatif dan menyenangkan itu diarahkan untuk mencapai tujuan pembelajaran. Efektifitas pembelajaran ditentukan oleh sejauhmana tujuan pembelajaran dapat dicapai. Pembelajaran Menyenangkan adalah penyajian pembelajaran dalam bentuk permainan yang kreatif yang dikemas dalam suasana yang menggembirakan untuk menumbuhkan minat belajar peserta didik.
Menurut Jamaris (dalam Prakoso, 2017) motivasi dapat didefinisikan sebagai suatu tenaga yang mendorong dan mengarahkan prilaku manusia untuk mencapai tujuan yang akan dicapainya. Sedangkan Demista (dalam prakoso, 2017) menambahkan bahwa motivasi yatu hasrat yang paling dalam untuk menggerakan dan menuntun manusia menuju sasaran, membantu mengambil inisiatif dan bertidak sangat efektif serta bertahan menghadapi kegagalan dan frustasi. Dengan kata lain, melalui motivasi yang tinggi, seseorang selain akan aktif dan bersemangat saat bekerja danberjuang untuk mencapai tujuannya, namun juga bisa menghadapi kenyataan jika tujuan tersebut belum tercapai.

Menurut Sardiman (dalam Bayu, 2016) motivasi berasal dari kata "motif" yang artinya sebagai daya upaya yang mendorong seoran untuk melakukan sesuatu. Dengan kata lain motivasi dapat diartikan sebagai daya penggerak yang telah menjadi aktif. Dimana motivasi itu akan muncul pada saat-saat tertentu, terutama bila dibutuhkan untuk mencapai tujuan tertentu. Menurut Mulyasa (dalam Bayu, 2016) motivasi merupakan salah satu faktor yang dapat meningkatkan 
kualitas pembelajaran, karena peserta didik akan belajar dengan sunguhsungguh apabila memiliki motivasi yang tinggi.

Motivasi belajar merupakan salah satu faktor yang turut menentukan keefektifan dalam pembelajaran. Seorang peserta didik akan belajar dengan baik apabila ada faktor pendorongnya yaitu motivasi belajar. Peserta didik akan belajar dengan sungguh-sungguh jika memiliki motivasi belajar yang tinggi. Menurut Uno (dalam prakoso, 2017) yang menyebutkan bahwa motivasi belajar adalah dorongan internal dan eksternal pada siswa yang sedang belajar untuk mengadakan perubahan tingkalaku, pada umumnya dengan beberapa indikator atau unsur yang mendukung. Nurhayati (dalam soewono, 2018) berpendapat bahwa motivasi belajar adalah suatu dorongan atau usaha untuk menciptakan situasi, kondisi dan aktivitas belajar karena didorong oleh adanya kebutuhan untuk mencapai tujuan belajar. Sehingga jelas bahwa motivasi belajar merupakan dorongan seseorang dalam kesiapannya untuk melakukan proses perubahan perilaku berdasarkan pengalaman tertentu.
Menurut Sardiman (dalam Bayu, 2016) ada tiga fungsi motivasi:

1. Mendorong manusia untuk berbuat, jadi sebagai penggerak atau motor yang melepaskan energi.

2. Menentukan arah perbuatan, yaitu kearah tujuan yang hendak dicapai.

3. Menyeleksi perbuatan, yaitu menentukan perbuatan-perbuatan apa yang harus dikerjakan yang serasi guna mencapai tujuan dengan mengesampingkan perbuatan yang tidak bermanfaat bagi tujuan tersebut.

Sedangkan fungsi motivasi menurut Oemar Hamalik (dalam Prasaja, 2017) adalah:

1. Mendorong timbulnya tingkah laku atau perbuatan. Tanpa motivasi tidak akan timbul perbuatan misalnya belajar.

2. Motivasi berfungsi sebagai pengarah, artinya mengarahkan perbuatan untuk mencapai tujuan yang diinginkan.

3. Menyeleksi perbuatan, menentukan perbuatan-perbuatan apa yang harus dikerjakan yang serasi guna mencapai tujuan, dengan menyisikan perbuatanperbuatan yang tidak bermanfaat bagi tujuan tersebut. 
Sehingga harapan terbesarnya adalah dengan menggunakan metode PAKEM diharapkan dapat meningkatkan motivasi belajar siswa kelas V SD Negeri 124 Batuasang pada masa pandemi ini.

\section{B. METODE PENELITIAN}

Jenis penelitian ini adalah penelitian lapangan (field research), yaitu penelitian yang dilakukan dengan terjun langsung ke lapangan untuk meneliti pengaruh penggunaan metode PAKEM terhadap motivasi belajar siswa. Metode yang digunakan dalam penelitian ini adalah metode eksperimen. Metode penelitian eksperimen dapat diartikan sebagai metode penelitian yang digunakan untuk mencari pengaruh perlakuan terhadap yang lain dalam kondisi yang terkendalikan.3 Desain yang digunakan dalam penelitian ini adalah preeksperimen (non-designs) yang belum merupakan eksperimen sungguh-sungguh, karena masih terdapat variabel luar yang ikut berpengaruh terhadap terbentuknya variabel terikat (dependen). Sedangkan bentuk dari desainnya adalah "pre-test dan post-test one group design" yaitu penelitian hanya menggunakan satu kelas eksperimen saja tanpa adanya kelas pembanding atau kelas kontrol. Dalam penelitian ini, metode eksperimen digunakan untuk mengetahui pengaruh penerapan strategi team quiz pada mata pelajaran Ilmu Pengetahuan Sosial di MI Ahmad Denan Kota Banjarmasin. Desain yang digunakan dalam one group design yakni penelitian yang dilakukan pada satu sempel penelitian yaitu kelompok eksperimen yang diberikan perlakuan pretes dan post-tes. Design ini dapat digambarkan sebagai berikut.

\begin{tabular}{|l|l|l|}
\hline P1 & X & P2 \\
\hline
\end{tabular}

Keterangan

P1 : Pretest

P2 : Posttest

X : Perlakuan

Penelitian ini dilaksanakan di SD Negeri 124 Batuasang, tepatnya Di Dusun Batuasang Desa Singa Kecematan Herlang Kabupaten Bulukumba. Populasi dalam penelitian ini adalah seluruh siswa kelas SD Negeri 124 Batuasang. Sampel adalah sebagian dari jumlah dan karakteristik yang dimiliki oleh populasi tersebut. Pada penelitian ini sampel diambil dengan menggunakan purposive sampling. Jadi sampel yang digunakan adalah seluruh siswa kelas V SD Negeri 124 Batuasang.

Teknik yang digunakan mengumpulkan data dalam penelitian ini adalah Observasi, Kuesioner atau Angket. Angket adalah sejumlah pertanyaan tertulis yang digunakan untuk memperoleh informasi dari respoden dalam arti laporan tentang pribadinya, atau hal-hal yang ia ketahui (Hermawan: 2019).

Untuk mengukur baik tidaknya sebuah instrumen diperlukan beberapa pengukuran seperi uji validitas dan realibilitas. Selain uji di atas ada lagi uji prasyarat yaitu uji nomalitas dan uji 
homogenitas. Setelah itu baru dilakukan analisis data dengan menggunakan uji paired sample t-test, tujuan dilakukannya paired sample t-test adalah untuk menguji apakah adanya pengaruh penggunaan elearning terhadap motivasi belajar siswa. Jika angka signifikansi lebih kecil dari 0,05, maka variabel independen tersebut mempunyai pengaruh signifikan terhadap variabel dependen. Jika angka signifikansi lebih besar atau sama dengan 0,05, maka variabel independen tersebut tidak mempunyai peningkatan signifikan terhadap variabel dependen.

\section{HASIL DAN PEMBAHASAN}

Data yang diperoleh dari hasil penelitian kemudian diolah. Data penelitian yang diperoleh adalah data tentang motivasi belajar siswa sebelum dan sesudah menggunakan metode PAKEM. Semua pengujian menggunakan bantuan aplikasi SPSS Dor Windows Versi 26. Kedua hasil tes kemudian dilakukan uji normalitas. Pada uji normalitas semua data normal. Ini dibuktikan dengan nilai sig yang lebih dari 0,05, sebesar 0,128. Begitu juga dengan uji homogenitas nilai sig lebih dari 0,05 yaitu sebesar 2,35. Setelah selesai melakukan uji prasyarat. Maka dilakukan uji hipotesis yaitu paired sample t-test.
Hasil penelitian motivasi belajar menggunakan angket dari pretest dan posttest diuji menggunakan SPSS For Windows Versi 26. Dari hasil uji tersebut ditemukan bahwa terjadi peningkatan motivasi belajar siswa jika dilihat dari rata-rata hasil motivasi, dimana pretest sebesar 86,58 menjadi 90,89. Sedengkan untuk melihat signifikansinya bisa dilihat pada nilai sig. jika nilai sig pda hasil tes paired sample t-tes kurang dari 0,05 maka ada peningkatan yang signifikan, tapi jika nilai sig kurang dar 0,05 maka tidak terjadi peningkatan yang signifikansi. Setelah melakukan uji paired sample t-test didapat nilai dig sebesar 0,589 yang berarti nilai sig lebih besar dari 0,05 yang artinya terdapat peningkatan motivasi siswa setelah penggunaan metode PAKEM. Menurut beberapa siswa yang diwawancarai bahwa metode PAKEM sangat menarik perhatian, karena metode baru yang didapat dan sangat menarik perhatian siswa.

\section{KESIMPULAN}

Berdasarkan data dan hasil penelitian setelah melakukan uji paired sample t-test menggunakan SPSS for Windows versi 26 ditemukan bahwa dengan menggunakan metode PAKEM 
dapat meningkatkan hasil belajar secara signifikan karena merupakan metode bau yang didapat oleh siswa selama pandemi. Diharapkan para guru dapat mengadopsi metode PAKEM ini untuk pembelajaran selanjutnya.

\section{DAFTAR PUSTAKA}

Abubakar Ahmad. 2018. Penerapan Model Pembelajaran Pakem Untuk Meningkatkan Hasil Belajar Siswa Pada Pokok Bahasan Kisah Nabi Ibrahim. A.S. Dan Nabi Ismail A.S. di Kelas IV SD Negeri 5 Sandik. Jurnal Ilmiah Ilmu Pendidikan, 1 (3), 114-120.

Agip, dkk. 2009. Penelitian Tindakan Kelas Untuk Guru. Bandung : Yrama.

Asri, S. A. 2017. Telaah Buku Teks Pegangan Guru Dan Siswa Pada Mata Pelajaran Bahasa Indonesia Kelas VII Berbasis Kurikulum 2013. Jurnal Ilmu Bahasa, 3 (1), 70-82.

Haddar, A. G. 2016. Evaluasi Pelaksanaan Model Pembelajaran Aktif, Kreatif, Efektif Dan Menyenangkan ( PAKEM ) Pada Mata Pelajaran Pendidikan Agama Islam Di Sma Lazuardi Global Islamic School, Depok. Jurnal Pendas Mahakam, 1 (2), 144-164.

Handayani, S. E. \& Subakti Hani. Pengaruh Disiplin Belajar Terhadap Hasil Belajar Bahasa Indonesia Di Sekolah Dasar. Jurnal Basicedu, 5 (1), 151- 164.

Inawati \& Darningwati. 2020. Kemampuan Mahasiswa Menentukan Ide Pokok Paragraf Melalui Teknik
Skimming. Jurnal Bindo Sastra 4 (1), 6976.

Jainuddin, J. (2019). Peningkatan Hasil Belajar Matematika Melalui Latihan Menyelesaikan Soal Secara Sistematis Pada Siswa Kelas XI. IPA1 SMA Negeri 2 Sungguminasa. Klasikal: Journal of Education, Language Teaching And Science, 1(3), 44-52.

Kaban, H. R., dkk. 2021. Pengaruh Model Pembelajaran PAKEM terhadap Hasil Belajar Siswa di Sekolah Dasar. Jurnal Basicedu, 5 (1), 102-109.

Laksmi, A. M. P. N., dkk, 2020. Pengaruh Model Pembelajaran PAKEM Berbasis Tri Kaya Parisudha Terhadap Kompetensi Pengetahuan PPKN Siswa Kelas IV. Jurnal Adat dan Budaya, 2 (1), 20-31

Mulyono. 2018. Berprestasi melalui JPF ayo kumpulkan angka kreditmu. Yogyakarta: Budi Utama

Santika. 2019. Pengaruh Model Pembelajaran Cooperative Integrated Reading And Composition (Circ) Terhadap Kemampuan Menentukan Ide Pokok Paragraf Siswa Kelas V Sd Negeri 003 Pulau Kopung Kecamatan Sentajo Raya Kabupaten Kuantan Singingi. Jurnal PAJAR (Pendidikan dan Pengajaran), 3 (2), 306-312.

Sugiyono.2012. Metode Penelitian Kuantitatif Kualitatif dan R\&D. Bandung: Alfabeta

Sumayasa \& dkk. 2015. Pengaruh Implementasi Pendekatan Saintifik Terhadap Motivasi Belajar Dan Hasil Belajar Bahasa Indonesia Pada Siswa Kelas VI di Sekolah Dasar SE Gugus VI Kecamatan Abang, Karangasem. $e$ Journal Program Pascasarjana Universitas Pendidikan Ganesha, 5, 1-11. 